\title{
Tourism employment and poverty: revisiting the supply curve
}

\author{
MICHAEL RILEY ANd EdiTH SZIVAS \\ Faculty of M anagement and Law, School of M anagement, U niversity of Surrey, Guildford \\ GU2 7XH, UK. E-mail:m.riley@surrey.ac.uk; eszivas@surrey.ac.uk.
}

The authors argue that the theory of the downward-sloping supply curve for labour is relevant to explanations of labour market behaviour in tourism. The paper is founded on the work of Sharif (1986, 1991, 2000), who questioned the definition of subsistence and argued that, in certain conditions, the initial slope of the curve would be downwards. The authors ask whether tourism development could provide these particular conditions. An important distinction is made between the perception of management of the market being in surplus or abundance. If the downward-sloping supply curve is the case, then the distress selling of labour that it implies would have implications for the quality of tourism products and for the capacity of tourism to alleviate poverty.

Keywords: tourism employment; poverty; mobility

This paper highlights the relevance to tourism employment of the concept of the downward-sloping supply curve for labour. The paper is founded on the work of Sharif (1986, 1991, 2000), who extended the idea as an explanation of the labour market behaviour of the working poor. Our perspective is from the micro level, that is, the individual selling his or her labour, and our concern is to argue that this abnormal supply curve is relevant to tourism development and quality. Tourism is often associated with the creation of new jobs. H owever, the creation of new jobs alone does not lead automatically to the creation of wealth for the indigenous population because new jobs may not provide an acceptable standard of living, which in turn leads to an abnormal extension of effort in terms of hours worked. Our view of tourism relieving poverty is not from the perspective of economic models but from the micro level of unskilled labour, a category which is often ill-defined and under-analysed by official statistics. The returns to unskilled workers are less than those to other tourismrelated occupations such as skilled workers or entrepreneurs, even when the industry is expanding (Blake et al, 2008). Our rationale for this assertion is based on the nature of the unskilled occupations and the labour market dynamics they promote.

The basic proposition is that the supply curve can slope downwards, indicating that people extend supply as the rate of pay declines. The argument 
is that this curve does not replace the conventional upwards-sloping form but can, in certain circumstances, be the initial stage of the curve. This does not mean that it is necessarily of short duration. At the centre of Sharif's argument is a constellation of three assumptions. Firstly, that the lowest point on the supply curve that functions to attract labour into the market may not accord with any acceptable level of subsistence. Secondly, the idea that acceptance of a level of subsistence is self-defined and therefore open to reinterpretations driven by the motivational dispositions of the individual. Thirdly, that market circumstances can exist whereby labour is so abundant that it deters technological substitution and has the effect of simultaneously deflating levels of pay and providing such turbulence in the market to convince the sellers of labour that there are open-ended opportunities for work.

Sharif distinguished the working poor from non-poor workers in behavioural terms through the notion of 'distress selling' of labour. The term 'distress' is used here to represent the idea that, for the poor, there is no realistic leisure option; even for women with children. He argues against the classical economic argument that failure to enter the market is due to 'irrational limited aspiration'. That the poor have an option for leisure is, for Sharif, only realistic in cases of strong welfare societies and rarely appears in devel opment situations. We argue that the circumstances of tourism, and particularly tourism development, may fit the notion of an abundant labour market which promotes the conditions of distress selling. It might not be easy for the image of tourism to accept that some of its workers are 'working poor' but, given that the average earnings are always well below national averages, it is a realistic view that they are (Riley et al, 2002).

\section{The downward-sloping supply curve}

Sharif $(1991,2000)$ terms the downward sl ope of the curve the 'forwards-falling' curve and contrasts it with the normal curve using a set of premises that simultaneously describe a constellation of market conditions. The premises are:

(1) That the bottom point of any normal supply curve is a line identifying the wage rate that is supposed to draw people into the market. This wage rate, however, does not automatically provide a subsistence wage. It cannot be regarded as a reserve wage guaranteeing an acceptable standard of living.

(2) That there is a difference between surplus labour and abundance whereby, with surplus labour, the total amount of work in the economy is shared and differentiated by rules that mean in practice that at the lower end there is a lot of part-time work. Abundance, by contrast, implies labour is abundant relative to other means of production; so plentiful that it deters technological substitution. In these conditions, the wage rate can be driven down by the market to below subsistence level.

(3) That what constitutes subsistence level and standard of living is determined subjectively; subsistence is self-defined (Sharif, 1986). It follows, therefore, that this condition is not confined to the working poor.

Sharif goes on to argue that the conditions specified in (1) and (2) produce 'distress' selling of labour. And, it follows logically from (3) that this can occur 


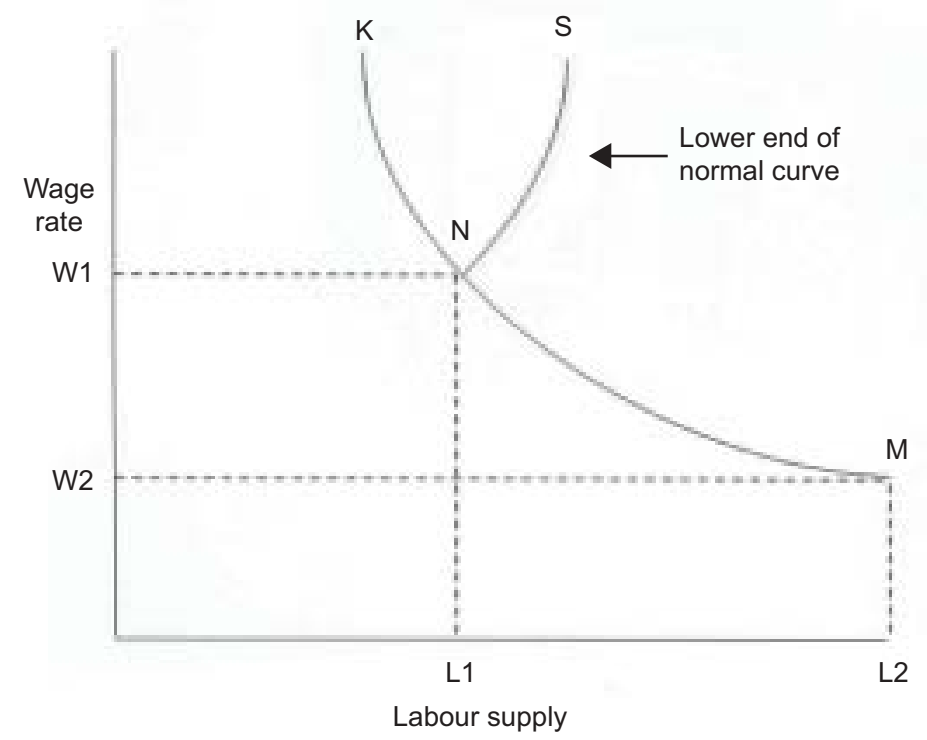

Figure 1. Adapted from Sharif's forwards-falling curve (Sharif, 2000, p 427).

at any level of pay, as long as it does not satisfy the self-defined subsistence or acceptable standard of living. The idea of a downward-sloping curve does not challenge the normal supply curve for labour (upward-sloping then backwards-bending) - which has at its lowest point on the curve the amount of pay capable of drawing the individual into, say, a tourism job performed at the lowest level of effort. It does, however, suggest the possibility of reinterpreting motives at the very low point of the normal curve. The assumption of this curve is that the low point represents some kind of subsistence level wage or reservation wage that is acceptable. There is, in fact, no guarantee that this point at which peopl e take up work actually provides an acceptable standard of living. Sharif argues that when it does not, consideration should be given to a different supply curve that shows a negative relationship between wage rates and the amount of labour supplied - more is supplied for less pay. In this conception, the curve falls forward in a gentle downward slope.

Figure 1 describes the forwards-falling curve based on the existence of the conditions (1), (2) and (3) described above. In the figure, M represents the lowest possible survival rate at $W 2$. The curve falls forward towards $M$ as people increase effort to gain as much as is possible in conditions where management can take advantage of abundance in supply. N S represents the lower end of a normal supply curve; the assumption of this figure is that $\mathrm{N}$ does not represent an adequate standard of living. If $\mathrm{N}$ did represent an acceptable standard of living, then the distress selling of labour is confined to the area under the curve $\mathrm{N} \mathrm{M}$. It can be argued that the same phenomenon could be represented simply by the normal curve being moved to the right, but that simply creates the same issue elsewhere if the end point of the curve does not satisfy subsistence.

H owever, by arguing that the level of subsistence is self-defined, he is making it harder to delineate the behaviours represented by the two curves. 
One interpretation of his analysis suggests that the downward curve represents those striving to achieve an acceptable subsistence level, never mind an acceptable standard of living (for themselves or their family). Consequently, it is the pursuit of the latter that makes the curve slope upwards in the normal way. However, in terms of motives, the change, for the individual, from a goal of subsistence to one of an acceptable standard of living would be seen as a single pursuit judged at evaluative stages. Certainly, the two curves are seen as part of the same supply drive but, for the individual, the point at which the curve slopes upward is a not a predictable certainty in the short run. A prominent theme within the human resource management literature is a concern for work-life balance, with its implication of pressure in the modern working environment for individuals to be overcommitted to work and to extend supply in a way which is detrimental to other aspects of life (Campbell, 2002). This concern assumes that employees have a degree of choice about their hours at work and can resist the 'long hours culture' if they choose. The arguments on the downward supply curve assume that there is not realistic choice other than to extend hours of work. W hat Campbell is describing is, in fact, a downward-sloping curve.

\section{The tourism labour market context}

How far the tourism secondary labour market conforms to Sharif's notion of abundance is a matter for research, but the evidence on the character of such markets, though indirect and circumstantial, points consistently in the same direction. Firstly, there is evidence that the secondary market for tourism occupation conforms to the unstable characteristics described by Doeringer and Piore (1982), namely high velocity interfirm labour turnover by uncommitted workers encouraged by management adopting weak internal labour markets. Secondly, as a consequence of the easy accessibility of skills, the labour is al ways in surplus supply (Riley, 1991). Empirical evidence shows that tourism is a relatively easy industry to access. The low skill level, multiple job types and a turbulent labour market are seen as the principal causes of the market's openness. This attraction is despite the constant deflationary pressures on pay within the tourism industry structure (Riley and Szivas, 2003). Indeed, one of the dominant arguments to explain low pay is that the labour market is al ways kept in surplus, if not abundance, by the nature of the work. Recruitment difficulties inevitably are resolved without recourse to increasing pay (Riley, 1990). Thirdly, that despite the low level of innovation, the labour-intensive nature of industry encourages management to use technological change, not simply to lower employment levels but also to substitute lower paid workers for the higher paid. Alpert (1986) showed that the reduction in employment caused by an increase in the minimum wage was offset by technological substitution, leading to increased employment of more cheaper, lower-skilled workers. This finding is in line with Rosen's notion that when skills are easy to acquire, there is no need for management to buy higher productivity in the labour market (Rosen, 1972).

To a large extent, tourism secondary labour markets are deregulated, but what gives them the capacity to be abundant rather than mere surplus markets 
is reputational information. Attraction itself is caused by the reputation for open-ended access to all levels of human capital (Szivas and Riley, 1999; Szivas et al, 2003; Vaugeois and Rollins, 2007). High-velocity labour turnover, together with the short-term fluctuations in demand, means that there are al ways vacancies to be filled and, if not, they will be along shortly; there is al ways opportunity to earn more (Fry, 1979; Segal and Sullivan, 1997; M anning, 2000). If this dynamic causes an attraction to the market, then this could foster an orientation within management not to seek technological substitution because of the certainty of constant supply. The issue of entrepreneurs ignoring progressive technology in favour of unskilled labour is acknowledged in the literature of economic development (Rosenberg, 1991; Recio and Banyulis, 2004).

\section{Applications of the curve}

There are two cases where this curve may be applicable. In the first case, where the level of pay is the sole income and does not give a subsistence standard of living and where the opportunity for a higher pay level is not possible. In these circumstances, workers put in extended hours to get as much as is possible from what is available, towards $M$. This would apply just as well to a selfdefined subsistence level. Thozhur et al (2007), in their study of low-paid workers (including tourism workers), provide some evidence of this with workers using extended hours (without overtime) double and sometimes treble jobbing. In short, this case is about working very hard to keep up a self-defined minimum standard of living.

In the second case, the limitation is by either a finite amount of work available, in which case workers compete to get as big a share as possible in terms of pay and hours, or where the rewards are distributed by some cultural judicial norm that does not recognize comparative effort. In other words, where either the total pay is fixed irrespective of who earns, or where regulation occurs that ignores actual worker contribution. For example, there can be conflicts within internal divisions of an indigenous population sharing a fairly fixed amount of reward (Van den Berge, 1992). In other words, 'distress' selling is a two-way valve - having to work longer to scoop as much as possible from the pool and having to work extended hours for a fixed amount simply to maintain the pool. Similarly, where tourism is based on community activity or a family firm, then everyone cooperates to give each member a share of the pot - in these circumstances, people give their labour knowing their share is not optimal and may not be meeting their personal target earnings. In short, this case is about knowing there is a finite amount and/or acknowledging that the finite amount should be shared within the group by some means unrelated to just effort.

In both cases, there is a 'distress' element to the selling of labour. There is both an important condition and an important consequence to this concept of 'distress' selling. The condition is that the self-definition of an adequate standard is influenced by other sources of income, and possibly capital. Often, tourism incomes are mixed in with other sources. A full understanding of tourism incomes and their relationship to labour supply requires these other sources, 
such as agriculture, family and community, to be considered. Indeed, many tourism products are built out of capital owned by the poor. The consequence is the effect on the quality of tourism products from a workforce that is selling its labour in a distress condition: an unresponsive labour force is a drag on economic development (M iracle and Fetter, 1970). The two cases of insufficient income and a finite pot of rewards when taken together with the presence of broader deflationary pressures suggest that, at least theoretically, the response of extending labour supply can occur in both a developed and underdeveloped tourism situation.

\section{Migration effects}

The link between self-defined subsistence and mobility is through the effort rewards relationship described through the supply curve. The paper argues that there are three thresholds that, when crossed or exceeded, create the drive to move on to another tourism destination or out of the industry. These are, when extended supply does not bring forth an acceptable level of subsistence, when the bonds of community are stretched by a just and traditional distribution system that neither provides enough work nor enough income and when the absolute value of incomes does not reach an acceptable level. The paper argues that income that is insufficient to reach the bottom level of the normal curve leads first to the distress selling of labour, then to the option to be in some way mobile. This is seen only as a special case of the general theory relating pay to mobility. That is, that the attendant motives are attributed, in the structural sense, to economic and knowledge/skill differentials and, in the psychological sense, to individual drives, which can be either of a self-advancing or of a deprivation avoidance character. In other words, the perceived differential, whether it be greater earnings, more knowledge or better life chances, can evoke a positive need for self-enhancement or a negative one to avoid the consequences of being deprived by the differential (Mueller, 1982; Szivas and Riley, 1999).

The desire to be mobile does, to an extent, require a target. Models of migration suggest productivity differentials cause income differentials, resulting in mobility until equilibrium is established (H arris and Todaro, 1970). One of the limitations of such models is that two secondary markets are assumed to have the same dynamics, which we argue is not the case. Dynamic instability in a market is attractive because it brings a degree of certainty about employment opportunities. If mobility and migration are related to the distress selling of labour in an industry where access is easy, it is possible to see a syndrome in which the very act of mobility undermines its ultimate purpose. Ease of access itself means that tourism is an area of opportunity, added to which it is also attractive to many people who are drawn to its lack of routine and its air of glamour. These supply-side characteristics, however, bring their own problems, particularly in the area of pay and black market employment (Stalker, 1994; Riley, 2004).

W hether at national or regional level, there is always a concern for the effect of inward migration of labour on the indigenous population. At the forefront of this concern is the displacement of local workers by newcomers, and 
consequent unemployment. Given that the motives for recruitment of outsiders are normally a perceived shortage of labour, the important effect is not only on employment levels, but also on the pay levels. The two issues are linked inexorably and, unfortunately, the empirical evidence here tells a slightly ambiguous story. For the skilled indigenous labour, the effects of imported skilled labour appear to be beneficial both in terms of extending job opportunities and increasing pay. Both presumably caused by the labour shortage that motivated the migration in the first place. H owever, the evidence of similar positive effects is somewhat less strong for unskilled workers (Pedace, 1988). Here, the argument is that, on the one hand, imported skilled labour reduces the opportunities for development of unskilled workers but, on the other, and more importantly, where unskilled labour is imported to fill a shortage, the effect is to deflate existing pay levels. At the moment, the evidence for the latter remains only conceptual and circumstantial but is, nevertheless, strong. By importing labour, the industry enforces deflationary pressure on pay, to the extent that incomes may not meet the expectations of the incoming workers. They may increase their standard of living marginally, but still may be forced to extend labour by distress selling.

\section{Discussion}

The basic tenet of this paper is that any debate on the contribution of tourism to the wealth of a local population has to recognize that some circumstances can promote the distress selling of labour. These conditions occur when management perceive the labour market to be abundant and therefore can drive wage rates down, even when the industry is expanding. They can also occur when cultural norms create a system of distributing work and reward that gives only suboptimal rewards to each worker. One of the intentions of the paper is to emphasize that extended hours of work are a consequence of the unskilled nature of the majority of tourism occupations, which elicits a response from human resource management that maintains the conditions for the distress selling of labour (Riley and Szivas, 2009). Models of migration underestimate the dynamic characteristic of secondary labour markets and that such markets can be differentiated by the way this is perceived; it can be both a deterrent and an attraction to market participation.

A secondary purpose of the paper is to draw attention to the effects of tourism on indigenous culture. The impact of tourism on cultural norms needs to be cognizant of changes in income distribution within social groups. Traditional reward systems tend to be defined culturally by norms rather than by market dynamics. Such norm structures can create the condition of finite work and reward, which means suboptimal effort and reward. The consequent tension between a traditional structure and a market-driven distribution system requires further research. Tourism not only changes wealth, but also traditional structures of distribution.

The contribution of this paper is to the debate on if, and how, tourism affects the wealth of its labour force. We suggest that official statistics and skill categories hide the different dynamics of secondary labour markets and argue that understanding relative pay, mobility and poverty relief needs to 
acknowledge that conditions can occur when the rewards to unskilled labour in terms of earnings are dependent on a willingness to extend labour supply, even when pay levels are declining.

\section{References}

Alpert, W.T. (1986), T he M inimum Wage in the R estaurant Industry, Praeger, N ew York, pp 103-110. Blake, A., A rbache, J.S., Sinclair, M.T., and Teles, V. (2008), 'Tourism and poverty relief', A nnals of Tourism Research, Vol 35, No 1, pp 107-126.

Campbell, I. (2002), 'Puzzles of unpaid overtime', in Zeytinoglu, I.U ., ed, Flexible W ork A rrangements: Conceptualizations and International Experiences, K luwer Law International, London, pp 25-44.

Doeringer, P.B., and Piore, M.J. (1982), 'Theories of the low-wage labor market', in Reynolds, L.G., Masters, S.H., and M oser, C.H., eds, L abor E conomics and Labor M arkets, Prentice-Hall, Englewood Cliffs, NJ, pp 60-66.

Fry, J. (1979), 'A labour turnover model of wage determination in developing economies', The Economic Journal, Vol 89, pp 353-369.

Harris, J., and Todaro, M. (1970), 'M igration, unemployment and development: a two-sector analysis', A merican Economic Review, Vol 60, No 1, pp 126-142.

Manning, A. (2000), 'Pretty vacant: recruitment in low-wage labour markets', Oxford Bulletin of Economics and Statistics, Vol 62, Special Issue, pp 747-770.

Miracle, M.P., and Fetter, B. (1970), 'The backward-sloping labour supply function and African economic behaviour', Economic D evelopment and Cultural Change, Vol 18, No 2, pp 240-251.

Mueller, C.F. (1982), The Economics of Labour M igration; A B ehavioural A nalysis, Academic Press, London.

Pedace, R. (1988), 'The impact of immigration on the labour market for native-born workers: incorporating the dynamics of internal migration', Eastern Economic J ournal, Vol 24, No 4, pp 446-462.

Recio, A.A., and Banyulis, L.J. (2004), 'Employment without technology? The paradox of the Spanish labour market', Economia e Lavoro, Vol 38, No 1, pp 115-137.

Riley, M. (1990), 'The labour retention strategies of UK hotel managers', The Service Industries Journal, Vol 10, No 3, pp 116-119.

Riley, M. (1991), 'An analysis of hotel labour markets', in Cooper, C., ed, Progress in Tourism, Recreation and H ospitality M anagement, Volume 3, Belhaven Press, London, pp 232-246.

Riley, M., (2004), 'Labour mobility and market structure', in Lew, A., H all, M., and W illiams, A., eds, A Companion to Tourism, Blackwell, Oxford, pp 135-145.

Riley, M., and Szivas, E. (2003), 'Pay determination: a socio-economic framework', A nnals of Tourism Research, Vol 30, No 2, pp 446-464.

Riley, M., and Szivas, E. (2009), 'The valuation of skill and the configuration of HRM', Tourism Economics, Vol 15, No 1, pp 105-120.

Riley, M., Ladkin, A., and Szivas, E. (2002), Tourism Employment: A nalysis and Planning, Channel View Publications, Clevedon.

Rosen, S. (1972), 'Learning and experience in the labor market', J ournal of H uman Resources, Vol 7, No 4, pp 326-342.

Rosenberg, R. (1991), 'Labour inferiority, economic development and factor proportions problem', $M$ anchester School of Economic and Social Studies, Vol 59, No 2, pp 146-159.

Segal, L.M., and Sullivan, D.G. (1997), 'The growth of temporary service work', The J ournal of Economic Perspectives, Vol 11, N o 2, pp 117-136.

Sharif, M. (1986), 'The concept and measurement of subsistence: a survey of the literature', W orld D evelopment, Vol 14, No 5, pp 555-577.

Sharif, M. (1991), 'Poverty and the forwards-fall ling labor supply function: a microeconomic analysis', W orld D evelopment, Vol 19, No 8, pp 1075-1093.

Sharif, M. (2000), 'Inverted "S", the complete neo-classical labour-supply function', International Labour Review, Vol 139, No 4, pp 409-435.

Stalker, P. (1994), The W ork of Strangers. A Survey of International Labour M igration, International Labour Office, Geneva, p 96.

Szivas, E., and Riley, M. (1999), 'Tourism employment in conditions of economic transition: the case of Hungary', A nnals of Tourism Research, Vol 26, No 4, pp 747-771. 
Szivas, E., Riley, M., and Airey, D. (2003), 'Labor mobility into tourism: attraction and satisfaction', A nnals of Tourism Research, Vol 30, No 1, pp 64-76.

Thozhur, S., Riley, M., and Szivas, E. (2007), 'Do the poor wake up quickly? A study of low pay and muted horizons', The Service Industries J ournal, Vol 27, No 2, pp 139-150.

Van den Berghe, P.L. (1992), 'Tourism and the ethnic division of labour', A nnals of Tourism R esearch, Vol 19, pp 234-249.

Vaugeois, N., and Rollins, R. (2007), 'M obility into tourism refuge employer?', A nnals of Tourism Research, Vol 34, N o 3, pp 630-648. 